\title{
Knowledge and Perception of Malaria Among Hausa Married Men in Mokola Community of Ibadan, Oyo State, Nigeria
}

\author{
Hayatudeen Muhammad ${ }^{1,2 *}$, Oyediran Emmanuel Oyewole ${ }^{1}$, Isaac Oluwafemi Dipeolu ${ }^{1}$
}

${ }^{1}$ Department of Health Promotion \& Education, Faculty of Public Health, University of Ibadan, NIGERIA

${ }^{2}$ REACH Initiative, ACTED, NIGERIA

*Corresponding Author: hayatu2478@gmail.com

Citation: Muhammad, H., Oyewole, O. E. and Dipeolu, I. O. (2021). Knowledge and Perception of Malaria Among Hausa Married Men in Mokola Community of Ibadan, Oyo State, Nigeria. European Journal of Environment and Public Health, 5(2), em0085. https://doi.org/10.21601/ejeph/11095

\section{ARTICLE INFO}

Received: 24 Mar. 2021

Accepted: 29 Apr. 2021

\begin{abstract}
Malaria is endemic in most countries within the African continent and accounts for high morbidity and mortality in those countries. The Nigerian Government launched the National Malaria Strategic Plan 2014-2020 to address the high burden of malaria in the country. However, like the previous plans, this plan focused more on the vulnerable groups to malaria (i. e. pregnant women, children under five years old and people living with HIV/AIDS) as the target population for the interventions. Men being the heads of the family in most African societies make all health decisions for the family. Many interventions that did not involve men do not succeed because of the decision roles men play in the family. An understanding of the knowledge and perception of men regarding malaria causes prevention, and management would assist in developing interventions aimed at reducing morbidity and mortality related to the disease in the community as well as achieving the Sustainable Development Goal 3.3, which focuses on Ending the Epidemic of Malaria.

Therefore, this study was designed to investigate the knowledge and perception of malaria among Hausa married men in Mokola community, Ibadan.The study was a descriptive cross-sectional survey. A three-stage sampling technique was used to recruit 302 Hausa married men based in Mokola; stratified into the Hausa and Yoruba (Okesu) axis, systematic random sampling was used to select the houses and balloting was used when a house had more than one married man. A validated semi-structured interviewer-administered questionnaire was used for data collection. Knowledge, perception and preventive practices were measured on a 22-point, 26-point and 14-point scales, respectively. Knowledge scores of $1 \leqslant 13$ and scores $>13$ were categorized as poor and good, respectively. Perception scores of $0 \leqslant 16$ and scores $>16$ were categorized as poor and good, respectively. Preventive practice scores of $0 \leqslant 8$ and scores $>8$ were categorized as poor and good, respectively. Data was analyzed using descriptive and inferential statistics such as Chi-square test at $p<0.05$ level of significance. Respondents' mean age was 36.4 years, with trading accounting for $97.7 \%$ respondents' occupation. Respondents whose monthly income range from N30,000N75,000 accounted for $56.0 \%$. Monogamy was practised by $75.5 \%$ with $73.2 \%$ having less than 5 children. Most respondents (76.2\%) correctly defined malaria, with $22.2 \%$ obtaining information on malaria from the electronic media. Majority (99.3\%) of respondents acknowledged to buying of drugs as one of the roles men should play in the treatment of malaria in their households. Most respondents, $89.1 \%$, had good knowledge on definition of malaria and $97.0 \%$ had a good perception towards malaria management in their families with $51.6 \%$ of respondents reporting that a family member had malaria less than a month ago. Respondents who used ITN as prevention against malaria for their families accounted for $80.8 \%$. Overall, $78.5 \%$ of respondents practised right preventive practice against malaria. The test of association between level of education and knowledge of malaria showed that only knowledge on symptoms of malaria was associated with the respondents' level of education $(\mathrm{p}=0.012)$. Test of association between level of education and perception of malaria revealed that perception of the respondents on causes of malaria was significantly associated with their level of education $(p=0.003)$. The test of association between respondents' knowledge and perception on malaria revealed that knowledge and perception were significantly associated $(p<0.001)$, also the test of association between knowledge and the preventive practices of respondents revealed a statistically significant association exists between knowledge level and preventive practices against malaria $(\mathrm{p}=0.028)$.

Majority of respondents had good knowledge and perception on malaria and only few reported practicing malaria preventive measures involving spending money for their households. Interventions such awareness through the electronic media and community mobilization on malaria preventive measures focusing on men should be carried out in other communities.
\end{abstract}

Keywords: malaria, knowledge, perception, predisposing factors, enabling factors, reinforcing factors, Mokola

\section{INTRODUCTION}

\section{Background to the Study}

Malaria is a life-threatening disease caused by parasites that are transmitted to people through the bites of infected female Anopheles mosquitoes. It is one of the most important causes of morbidity in the world and it is caused by eukaryotic protists of the genus Plasmodium. The female Anopheles mosquitoes carry the Plasmodium parasite in their salivary glands (Okwa et al., 2012). The spread of malaria has been linked to factors such as the socio-economic status, knowledge of malaria, and also protective behavior (Kinung'hi et al., 2010).

In Nigeria, families are the primary context within which most health problems occur and have a powerful influence on health. Most health belief and behavior are developed and 
maintained within the family and community (Campbell et al., 2002). Family perceptions, beliefs, and attitudes about malaria prevention, causation, symptom identification and treatment, influence efforts to address malaria and are often overlooked in control efforts (Deressa et al., 2003). It varies from community to community, but similar in individual households in the same community (Rodriguez et al., 2003). In a typical African community, men are the leaders of the family and make all decisions with regards to the family life and welfare, therefore an understanding of men's knowledge as it relates to malaria is very important.

Considering these issues it can be an important step towards developing strategies aimed at controlling the malaria. Understanding family leaders (men) who already know about malaria and malaria prevention, who have adopted malaria prevention and mosquito avoidance practices, and who are at risk of malaria infection is a necessary precursor to identifying and targeting vulnerable populations and ensuring successful implementation and sustainability of malaria control efforts (Rupashree et al., 2014).

In a study conducted in Ondo state by Saheed et al. (2015), 92.1\% of the respondents attributed malaria to be a mosquitoborne infectious disease, 27.0\% reported female Anopheles mosquito as the type of mosquito responsible for malaria. Regarding malaria knowledge, 97.1\% stated that malaria can be prevented while $2.3 \%$ of respondents reported that malaria cannot be prevented. In another study conducted in SouthWestern Nigeria, some family heads attributed causes of malaria to hunger and fatigue (6.0\%), bathing with hot water (5.0\%), houseflies (6.0\%), and all insects (13.0\%) and eating certain types of food (15.0\%) (Abd/El-Gayoum et al., 2009). This erroneous perception as to the cause of the disease has led to $80.0 \%$ of death caused by malaria occurring in SubSaharan Africa (WHO, 2017). Therefore, this study will investigate the knowledge and perception of malaria among Hausa married men in Mokola community of Ibadan, Oyo state.

\section{Problem Statement}

Malaria is endemic in most countries and accounts for high morbidity and mortality globally. In 2015, an estimated 211 million cases of malaria occurred globally, while in 2016; 216 million cases of malaria occurred. The American and Africa continents accounted for nearly $70 \%$ of the countries that had increases of more than 20\% in 2016 compared with 2015 (WHO, 2017).

Poor knowledge of causes, prevention, and treatment of malaria among married men has made it a priority disease in Nigeria responsible for high morbidity and mortality annually. According to WHO malaria factsheet, Nigeria accounted for $27 \%$ of global malaria burden in 2016 (WHO, 2017).

Preventive measures for malaria, such as the use of insecticide treated nets are perceived from different perspective among married men. In a study conducted by Titiloye., Onuosa and Arulogun, 2017 in two army barracks in Ibadan in 2017, 93.7\% of respondents knew insecticide treated nets were used to treat malaria and $2.8 \%$ thought ITN was simply to beautify their houses while another $1.0 \%$ thought ITN were simply to create warmth.
The state of public hospitals in most states in Nigeria is deplorable forcing many to seek care for malaria in private hospitals, though more expensive. In a study conducted by Salau, Fawole and Dairo, 2016 in Ibadan North LGA, 46.2\% of married men utilized the services of private clinics in treatment of malaria for themselves and their families. According to the Nigeria Demographic and Health Survey of 2013, children under age 5 and pregnant women are the groups most vulnerable to illness and death from malaria infection in Nigeria. These two population groups are the responsibility of men in African society as earlier pointed out, therefore an understanding of men's knowledge and perception as it relates to malaria is very important in reducing the morbidity and mortality from malaria.

This study aims to identify the gaps in the knowledge and perception of malaria among Hausa married men in Mokola Hausa community and recommend ways to address those gaps.

\section{Justification for the Study}

Many studies have been done to assess the awareness and knowledge of malaria in Nigeria but none has been done among Sabo married men in Mokola, Ibadan. Many intervention programs that did not involve men did not succeed because of the decision-making role men play in the family. Also, Sabo population rate could be growing exponentially. Therefore, assessment of malaria knowledge among Sabo men is important to allow for national planning and allocation of resources.

Malaria is responsible for the greatest morbidity in the community as could be seen from the health record in the maternity center in the community. This has led to several studies being carried out on the knowledge and perception of malaria among women in the community, but none has been carried out yet on the knowledge and perception of malaria among men in the community.

\section{Research Questions}

i. What is the level of knowledge of married men in Mokola community on malaria?

ii. What is the perception of married men in Mokola community about malaria?

iii. What are the preventive practices employed by men in Mokola community for malaria control?

iv. What are the factors influencing knowledge, perception and preventive practices of married men in Mokola community regarding malaria?

v. In what ways are men being involved in malaria control in the family?

vi. What information do men require on malaria control?

\section{Goal}

To investigate the knowledge and perception of malaria among Hausa married men in Mokola community of Ibadan.

\section{Specific Objective}

i. To assess the knowledge of married men on the management of malaria.

ii. To determine the perception of married men in Mokola community about malaria. 
iii. To discuss the preventive practices employed by men in Mokola community for malaria control.

iv. To explore the factors influencing knowledge, perception and preventive practices of married men in Mokola community.

v. To explain the ways in which men are involved in malaria control.

vi. To determine the types of health messages required by men.

\section{Research Hypotheses}

Ho1 There is no significant association between level of education and knowledge of management of malaria among married men in Mokola Hausa community.

Ho2 There is no significant association between level of education and perception of management of malaria among married men in Mokola Hausa community.

Ho3 There is no significant association between level of knowledge and perception of malaria among married men in Mokola Hausa community.

Ho4 There is no significant association between knowledge of married men and their malaria preventive practices.

\section{LITERATURE REVIEW}

\section{Malaria}

Malaria is a life-threatening disease caused by parasites that are transmitted to people through the bites of infected female Anopheles mosquitoes. Malaria prevention refers to specific efforts aimed at reducing the development and severity of malaria, while care seeking behaviours are actions undertaken by malaria patients to get the proper treatment in order to get well. According to the World Health Organization (WHO), malaria cases have risen from 211 million in 2015 to 216 million in 2016, with $90.0 \%$ been from the WHO African region. Indigenous malaria cases were reported from 91 countries and 15 of these carry $80.0 \%$ of the global malaria burden, all of which except India, are in sub-Saharan Africa (WHO, 2017). A total of 445,000 deaths were recorded as at 2016 and the 15 countries accounted for $80.0 \%$ of global malaria deaths in 2016; all of these countries are in subSaharan Africa, except India (WHO, 2017).

Studies related to barriers affecting uptake of malaria preventive measures indicate that despite the efforts made towards the control of malaria, compliance and sustenance are still below expectations mainly in most families in South Western Nigeria (Chukwuocha, 2012). This could possibly be due to wrong perception and knowledge about the disease among men who are the heads of the families. This could be shown by a study conducted by Oladimeji., Tsoka., Gengiah., Daftary and Naidoo, 2018 in Ibadan where male married participants in a focus group discussion alleged that mosquito nets were given by developed countries in order to kill their children and reduce their population. The findings of this study corroborates with a recent quantitative study in Northern Nigeria which showed that one of the reasons reported for non-adherence with malaria preventive measures included low environmental sanitation (Michael et al., 2017).

Mokola Community being a predominantly Muslim community with people of Northern extraction retains some Northern values which includes non-mixing of matured ladies, married women inclusive with men, not even for the purpose of learning health issues, unless the male is her husband, father, brother, child or a first degree relative. Therefore, identifying the gaps in male knowledge and perception as it relates to malaria would also address the female gaps in knowledge and perception as it relates to malaria. This could be shown by a study conducted by Ashikeni et al. (2013) in Northern Nigeria which found that adequate health education to women especially in the language they understood and also by their spouses effectively increased their knowledge and improved the practice of malaria treatment.

\section{Knowledge of Malaria among Married Men}

Knowledge about diseases is a crucial element in health improvement and the education of a disease-burdened group on the ways of disease prevention is important to the attainment of self-reliance in disease endemic countries (Iriemenam et al., 2011). Several studies have assessed different aspects of malaria including causes, risk factors, mode of transmission, prevention, management of cases e.t.c. A study carried out among married men observed a reasonable level of knowledge (49.7\% good) of malaria with mosquitoes or malaria parasite being recognized as a transmitter of malaria (97.2\%) (Abd/El-Gayoum et al., 2009). In the same study, others attributed causes of malaria to hunger and fatigue (6\%), bathing with hot water (5.0\%), houseflies (6.0\%), all insects (13.0\%) and eating certain types of food (15\%.0) (Abd/ElGayoum et al., 2009). In another study conducted in Cameroon, 99.0\% had heard about malaria with the health facility being the most popular source of information (74.0\%) among radio, television, tracts/posters and the community relay agents as all sources of information. The study also observed that majority (88.0\%) of respondents had good level of knowledge on malaria while (6.8\%) and (5.2\%) had average and poor levels of knowledge on malaria respectively and $88 \%$ knew at least one correct sign/symptom of malaria (Kimbi et al., 2014). Another study in Tanzania observed that the knowledge on malaria transmission, prevention, and treatment was reasonable; $56 \%$ of respondents associated the disease with mosquito bites (Mazigo et al., 2010).

In relation to knowledge on the signs and symptoms of malaria, the study by Abd/El-Gayoum et al. (2009) also revealed that households heads had a poor understanding of how to recognize malaria signs and symptoms, with (71.3\%) reporting feeling hot (Abd/El-Gayoum et al., 2009). In a study conducted in South-Western Nigeria, the respondents' knowledge on the symptoms of malaria as persistence headache, high temperature and shivering was the response of $94 \%$ while $6 \%$ said itching was among the symptoms of malaria infection. Non respondent agreed that bleeding was among the symptoms (Oluyemi and Oluyemi, 2017).

A study reported that knowledge regarding antimalarial therapy was generally limited. Only (53\%) of men who are married men knew Artesunate (AS) + Sulphadoxine Pyrimethamine (SP) combination is government's 
recommended first-line of treatment for malaria, $31.2 \%$ knew the correct dose of treatment, although treatment protocol was found in posters in all health centers and hospitals indicating that a high percentage of married men was knowledgeable about malaria and/or mosquitoes as a cause of fever but far less so knowledgeable about their correct management (Abd/El-Gayoum et al., 2009). The study by Mazigo et al. (2010) also observed that the majority of respondents reported to have heard of the combination therapy, artemether+lumefantrine (ALU) for treatment of malaria with health facilities being the main source of information.

Regarding knowledge of preventive practices, a study was conducted among non-medical students in South-Western Nigeria, 97.1\% stated that malaria can be prevented, 33 (2.3\%) students reported that malaria cannot be prevented, while 8 (0.6\%) students gave no response. The methods listed to prevent malaria by the students who stated that malaria can be prevented included reducing exposure to mosquitoes by the use of ITNs and indoor residual spraying (IRS) as a way of bite prevention, spraying the home with insecticides to help kill mosquitoes that find their way in, keeping a clean environment by ensuring bushes in surroundings are cleared and drainages cleaned up, use of preventative drugs, and health education, with most respondents mentioning at least one method. 774 (54.5\%) students have heard about IRS, 589 (41.4\%) have not heard about IRS, whereas others gave no response (Usman et al., 2015). According to Dlamini et al. (2017) knowledge of methods to prevent mosquito breeding is poor in a study carried out in Lomahasha.

\section{Perception on Malaria among Married Men}

The way individuals or group of people perceive or see things influences the decision they take as regards perceiving it as being serious, a threat or being susceptible. This is also applicable to diseases in relation to causes, mode of transmission, signs and symptoms, treatment, management and prevention. For instance, perception about malaria may differ among individuals as some people see it as it can easily be treated hence no need to seek medical attention and prefer to use over the counter drugs (McCombie, 2002). At a community level, however, a lot more complex factors influence prompt access to effective treatment besides availability and affordability (McCombie, 2002). An understanding or explanation of the illness in a way that is different from the biomedical explanation influences the decision regarding whether to seek treatment or not, and when and where to seek treatment (Tarimo et al., 2000; Makemba et al., 1996).

A qualitative study revealed the various perceived causes of malaria by individuals such as some people say if the rain beats you, you will have malaria; at times they also say it is a spiritual arrow from somebody that hates you; when they [children] walk under the sun and play in the sun it also causes this sickness of malaria; when you take oil (palm oil) too much, you get malaria (Oladimeji et al., 2018). According to Uzochukwu et al. (2018) in a study conducted in Eastern Nigeria, even though the community members had good knowledge of malaria symptoms, certain misconceptions still existed like the reliance on yellowish urine, bitterness of mouth, which are very subjective symptoms of malaria in adults and in children. In a similar study carried out among married men by Padonou et al. (2018) in Southern Benin, it was found that $9.3 \%$ and $9.4 \%$ attributed the cause of malaria to the sun and from body weakness respectively. Formal education plays a role in genuine knowledge about malaria as could be shown by a study conducted by Ndibuagu et al where $66.2 \%$ of people with formal education were aware that dirty environment leads to breeding of mosquitoes compared to $36.9 \%$ of those without formal education. In a community like Sabo where $54.4 \%$ of the male traders have no formal education at all, this would undoubtedly affect their knowledge about malaria (Aremu and Olugbire, 2015).

In seeking for treatment, some individuals believe they have to wait for some few days after noticing or experiencing symptoms before going to health institutions for medical intervention. In a study by Ajayi et al. (2008) conducted in Nigeria, most of the respondents reported that Artemether Lumefantrine (ALU) was the best treatment for malaria in children. Some individuals perceive ALU to have side effects. A study carried out in Tanzania observed that the perceived side effects of ALU by respondents were headache and dizziness, nausea, anorexia and abdominal pain, and arthragia ormyalgia (Mazigo et al., 2010). In a study conducted in South East Nigeria in which $29.7 \%$ of the respondents were males, it was found that $34.5 \%$ of educated male respondents knew that Artemisinin-based Combination Therapy is the recommended treatment for uncomplicated malaria infection (Ndibuagu et al, 2017).

\section{Preventive Practices against Malaria among Married Men}

Preventive practices recommended by the World Health Organization include; Vector control such as sleeping under insecticide-treated nets (ITNs), indoor residual spraying (IRS), in some specific settings, larval control e.t.c, early diagnosis and treatment and intermittent preventive treatment for pregnant women and infants and seasonal chemoprophylaxis for children 1-5 years of age.

According to the most recent malaria indicator survey conducted by the Nigerian national malaria program in 2015, ownership of long-lasting insecticide treated net (LLINs) was $69.0 \%$, of which $37.0 \%$ of the household slept under a LLIN the night before the survey. The survey results in addition showed that among women who attended antenatal care (ANC) for their most recent pregnancies, only $37.0 \%$ received two or more doses of Sulfadoxine-pyrimethamine (SP) (NPC, 2015).

A study in Ondo State Nigeria, observed that $2.0 \%$ of the participants sleep always under the treated net, $24.0 \%$ sleep under it every night, $30.0 \%$ occasionally sleep under it while $44.0 \%$ have never slept under insecticide treated net (Oluyemi and Oluyemi, 2017). In a study conducted in Cameroon, most respondents (57\%) used ITNs mainly for protection against mosquito bites while $48.0 \%$ used them for protection against malaria (Kimbi et al., 2014). According to Mazigo et al. (2010), bed nets were used by 236 (64.5\%), and usage was significantly associated with education level while the level of bed net ownership was $77.3 \%$. A study among married men reported that means of preventive measures were limited, as insecticides were used by (22.9\%) of respondents, followed by bed nets $(23.9 \%)$, whereas screened windows were used by 
quarter of the respondents (25.8\%) and (39.5\%) reported no attempt to use any preventive measures (Abd/El-Gayoum et al., 2009). Some studies reported that people used repellent coils, proper clothing that covers the whole body, spray and removal of stagnant water from the environment as preventive practices (Anand et al., 2014; Kirkby et al., 2013). However, some ethnic groups in some parts of South Africa equally preferred traditional methods, like making bonfires, burning grass, rubbing lamp or motor oil on the skin, and sleeping wrapped in wet chadors and applying herbal oil to avoid mosquito bites, are practices which were quite prevalent (Chourasia et al., 2014; Sabin et al., 2010). In a post campaign survey in Kano, it was found that a higher percentage of females (57.6\%) used ITNs compared to males (48.8\%) (Garley et al., 2013).

Several studies reported that delays in the diagnosis and treatment of malaria in women and children, even for a few days due to the insufficient knowledge of their husbands/fathers and in some cases the economic status of the men, this in most cases would lead to a fatal outcome (Ahmed et al., 2009; Dhawan et al., 2014). It has been discussed that the community people who suffered from malaria would rather wait for a few more days and help themselves with home remedies. When the disease did not seem to get better, then the men within the community would seek help from traditional healers (Joshi and Banjara, 2008; Tobgay and Lhazeen, 2010), these to the men is an economically wise decision. Although malaria affects both men and women in Sabo community, gender roles and gender dynamics give rise to different vulnerabilities, such as exposure patterns. For example, traditional gender roles involve men going to their shops very early in the morning and coming back at night which expose them to peak mosquito-biting times (Cotter et al., 2013).

\section{Factors influencing uptake of preventive and management practices for malaria among married men}

Knowledge, attitude and perception: The practice of malaria preventive measures has been related to the level of knowledge and belief of people. The understanding of the possible causes, modes of transmission and decision about adoption of preventive and control measures vary from community to community and among individual households (Erhun et al., 2005; Legesse et al., 2007). Knowledge, attitude and perception had been observed to influence prevention and management of malaria. However previous studies had reported low compliance of knowledge, attitude, perception and home management of malaria in semi urban Lagos, rural Lagos and Ibadan respectively (Fawole and Onadeko, 2001; Ibidapo, 2005; Otubanjo et al., 2000). A different view was observed in a study carried out among pregnant women attending antenatal care (ANC) in Lagos State, where improved knowledge, perception and attitude of the ANC women has influenced malaria symptoms and management. This finding is also similar to that of the studies carried out in Enugu and Oyo town (Adedotun et al., 2010; Oguonu et al., 2005). According to Oladimeji and colleagues in a study conducted in Ibadan, Nigeria, Knowledge on malaria causality and symptoms, prevention strategies, beliefs, fear of side effects from current malaria preventive measures, corruption and difficulty in obtaining nets, and poor environmental hygiene were some of the themes which emerged as barriers to the effective uptake of malaria prevention intervention.

Institution barriers: Another study conducted among pregnant women in two Nigerian states found that systemsbased challenges which includes essential medicine supplies stock outs, lack of provider knowledge on intermittent preventive treatment of malaria in pregnancy (IPTp) together with individual women's beliefs and lack of understanding of intermittent preventive treatment of malaria (IPT) contribute to low malaria intervention uptake and adherence (Diala et al., 2013)

Income: In Nigeria, out of pocket expenditure for health is the main source of financing for health and this is irrespective of the fact that majority of the populace live in abject poverty (National Bureau of Statistics, 2017). Undoubtedly, this has been identified as a barrier to accessing healthcare (Uzochukwu et al., 2015), hence in a study that involved government employees in southeast Nigeria, who were more enlightened than the average population, those who relied on out of pocket expenditure had difficulties assessing quality healthcare services (Oyibo, 2011).

It has been established that Artemisinin based Combination Therapy are more expensive when compared with the mono-therapies (Onwujekwe et al., 2010). This may influence the choice of anti-malaria use by the people in favour of mono-therapies. This has already been identified as a challenge in the fight against malaria (WHO, 2015). Also in a study by Mavis and Humphrey (2015), a statistically significant association was established using a chi-square test between participants' economic conditions (employment status and income earning status) and their malaria prevention and control practices. Scarcity of resources also influences preventive practices for example a community that has shortage of water supply has the tendency to store and preserve stagnant water which may be a breeding site for mosquitoes, hence this may influence their perception and preventive practices (Dlamini et al., 2015).

Lack of proper information and awareness on malaria: For instance, according to Uzochukwu et al. (2018), the delay of two or three days in seeking for treatment for symptoms suggestive of malaria among the participants may be attributed to the effect of a popular advertorial for a wellknown analgesic which was repeatedly aired on the electronic media and the message requested the populace to consult a physician after three days if symptoms persisted after the use of the analgesic. It is important to note that the advertisement was not for malaria treatment but may have been misunderstood by the people. At that period also, there was no emphasis on malaria diagnosis using rapid diagnostic test (RDT) or microscopy before treatment. Since the people are consciously holding on to the values of that advice, there may be the need for increased public awareness on the current World Health Organization guidelines on the diagnosis and treatment of malaria. This is important in changing the perception of the people on use of analgesics thus encouraging the members of the public to make right choices for malaria treatment. 
Prevalence of the disease: When people live with a disease for a long time, they tend to regard it as a part of their everyday life (Fungladda and Butraporn, 1992). This was supported by a study in Lomahasha that observed that some members of the Lomahasha community, such as footballplaying boys and alcohol imbibers, were so used to the disease that they perceived it as a part of their lives (Dlamini et al., 2015).

Other socio-demographic characteristics: A statistically significant relationship was found between age, education, type of dwelling and malaria prevention and control practices of the participants in a study by Mavis and Humphery (2015). However, no significant relationship was found between ethnicity and malaria prevention and control practices of participants (Mavis and Humphrey, 2015). Gender has also been observed to influence prevention and management practices of malaria. For instance, as it is a common practice in Africa that the Woman takes care of the home so she is indirectly responsible for the chores and care of every member of her household which is also applicable to malaria prevention as she mostly takes care of environmental and vector control practices. According to Dlamini et al. (2015), malpractices are more commonly observed among men and boys.

Factors Influencing Knowledge and Perception about Malaria among Married Men

A study carried out in Sudan established that married men knowledge in El Azergab area increases with education, property, and the economic status of the family in general (Salma et al., 2009).

Age has also been observed to influence knowledge and perception, this was confirmed by a study carried out in Lomahasha that stated that an information gap existed among those older than 50 years who still hold false notions about the etiology of malaria and hence seek for health assistance from wrong sources (Dlamini et al., 2015).

It has been documented that formal education improves overall knowledge of malaria among the populace. It is said that those with at least secondary school level of education could have been exposed to lessons on malaria in school, and also better place to read or comprehend malaria messages on print or electronic media (Adedotun et al., 2010; Erhum et al., 2010). A study carried out in Eastern Nigeria observed that up to $78.4 \%$ of respondents with a formal education knew that malaria is transmitted through mosquito bites, while only 42.0\% had the same knowledge among respondents without formal education (Edmund et al., 2017). This is also comparable to study in Tanzania where $22.8 \%$ of literate respondents, as against $3.7 \%$ of illiterate ones knew that malaria is transmitted through the bite of mosquito (Mazigo et al., 2010). Another study observed no significant difference in the level of knowledge of the same subject matter between individuals without formal education and their counterparts with formal education in a study carried out in Ghana (AppiahDarkwah and Badu-Nyarko, 2011).

According to Krishi et al. (2010), in a study conducted in Cameroon, the level of good knowledge in secondary/high school/university level respondents (91.0\%) was significantly higher than in non/primary level respondents (83.0\%).
Respondents with secondary/high school/university level of education were 2.1 times more likely to have a good level of knowledge on malaria than their none/primary level counterparts. Another study in Tanzania showed the same relationship between education and the level of knowledge of malaria (Mazigo et al., 2010). In a study conducted in Southwestern Nigeria, the difference between the knowledge on malaria complications such as anemia, among women attending ante-natal care in a government tertiary hospital, who have secondary school education and above; was very significant when compared to respondents without formal education (Atulomah et al., 2014). In the study by Edmund et al. (2017), few of the respondents with formal education (34.5\%) knew that Artemisinin based Combination Therapy is the recommended treatment for uncomplicated malaria infection and fewer number of those without formal education (17.8\%) had the same knowledge.

\section{Ways in Which Men are Involved in the Control of Malaria}

In a study conducted in Lomahasha by Sabelo et al, it was found that methods of malaria prevention and control mentioned by study participants included draining swamps and stagnant water (36.0\%), burying or destroying cans and tins in pits (25.0\%), clinic visits $(25.0 \%)$, use of bed nets (14.0\%), and spraying (11.0\%). In a typical Hausa community like Mokola, any activity done outdoor like draining of water ways, burning of refuse or involving material resources like purchasing sprays, paying for clinic visits etc are traditionally the responsibilities of men.

In most Nigerian communities, male preference for western education is an obvious fact. The level of knowledge on malaria is associated with level of education of an individual. Individuals who have attended at least primary school education are more knowledgeable than those without formal education. Married men (men) with low knowledge on malaria experienced 2.3 times more malaria cases in their households than those with higher knowledge (Leonard et al, 2010).

Hot weather was found to be the main barrier to ITN use in most Northern communities due to the clustered nature of housing in most Hausa communities (Michael et al., 2017). Young men who are not yet financially stable in Hausa communities stay in their parent's houses even after marriage thereby contributing to the level of congestion in most households and therefore the level of heat in such household. This negatively affects ITN use in such household due to the heat generated from its use.

\section{Information Required by Men Regarding Malaria Control}

Transmission of malaria depends also on climatic conditions that may affect the number and survival of mosquitoes, such as rainfall patterns, temperature and humidity. In many places, transmission is seasonal, with the peak during and just after the rainy season (Confaloneri et al., 2007), therefore proper knowledge on environmental factors such as proper disposal of stagnant water, disposal of waste, clearing bushes around residential environment e.t.c are required by men in effective malaria control. 
Wrong perception and knowledge about the disease among men have affected the uptake of malaria preventive measures in most families in South Western Nigeria (Chukwuocha, 2012). This could be shown by a study conducted by Oladimeji et al in Ibadan where married male participants in a focus group discussion alleged that mosquitoe nets were given by developed countries in order to kill their children and reduce their population. Proper and adequate information on the knowledge and perception of the disease among men is necessary for the compliance and sustenance of control measures.

In a study conducted by Abd/El-Gayoum et al. (2009) only (53.0\%) of men who are married men knew Artesunate (AS) + Sulphadoxine Pyrimethamine (SP) combination is the governments recommended first-line of treatment for malaria, such gaps in knowledge has also promoted quackery and the persistent use of chloroquine by some health professionals.

\section{Theoretical and Conceptual Framework}

In order to gain proper understanding into this study, PRECEDE Model was utilized.

The PRECEDE model is a planning model which offers a framework for identifying intervention strategies to address factors linked to the outcomes of interest. It does not however predict or explain the factors. It was developed by Green, Kreuter and associates. The model provides a road map for designing health education and promotion programs. The model views health behaviour as influenced by both individual and environmental forces. It guides planners through a process that starts with desired outcomes and works backwards to identify a mix of strategies for achieving objectives.

The PRECEDE acronym stands for Predisposing, Reinforcing, Enabling, constructs in educational/environmental diagnosis and evaluation. Developed in the 1970s, this component of the model thus posits that an educational diagnosis is needed to design a health promotion intervention, just as a medical diagnosis is needed to develop a treatment plan. This model assumes that since health promoting behaviours and activities that individuals engage in are almost always voluntary, carrying out health promotion has to involve those whose behaviour or action we want to change.

Application of this model is a participatory process involving those affected by the issue in question. Its relevance to this study is shaped by the explanation of this model that health is by nature a community issue, it assumes that health is an integral part of a larger context and it is within this context that it must be considered and also that health is more than physical well-being, it is a constellation of factors economic, cultural, social, ecological and physical which explains health behaviours and actions thereby affecting quality of lives of individuals, families and communities. Also, according to the framework, any behaviour is caused by some behavioural antecedents which are categorized into predisposing, enabling and reinforcing. The Precede Model was useful in classifying the factors influencing knowledge and perception of Hausa married on malaria. Ascertaining the possibility of sustaining male involvement in malaria prevention and control because of their decision-making role in the family.

To understand the involvement of married men in malaria prevention and control, the four assessment of PRECEDE phases was undertaken as follows:

Phase 1: Identifying the ultimate desired outcomeInvestigating knowledge and perception of malaria among Hausa married men in Mokola community of Ibadan.

Phase 2: Identifying factors and issues that may affect the outcome such as environment, cultural/religious factors and gender roles.

Phase 3: Identifying predisposing, enabling and reinforcing factors that affect behaviour of respondents and the environment at large.

Predisposing factors on knowledge and perception of Hausa married men in Mokola community include poor knowledge on preventive practices, symptoms and treatment of malaria, erroneous perception of malaria and large family size. Enabling factors include awareness on how malaria is been transmitted by health workers, regular awareness on prevention and symptoms of malaria by MPH students posted to the Mokola community and also awareness on radio stations on family planning in order to reduce family size and boost caregiving capacity. Reinforcing factors which may encourage sustainability include married men participating in the awareness program on malaria transmission, prevention and symptoms by health workers and MPH students have less malaria incidence in their households and also married men who listen to radio programs on family planning are better able to care for their family whenever they have malaria.

Phase 4: Identifying the administrative and policy factors that influence what can be implemented.

\section{METHODOLOGY}

\section{Study Design}

The study was a descriptive cross-sectional study aimed at assessing the knowledge and perception of married men in Mokola community on malaria. A descriptive study design is one in which its primary goal is to assess a sample at one specific point in time without trying to make inferences in order to identify areas for further research. It is a study in which the disease and the related factors are measured at a specific point in time for the defined population.

\section{Study Area}

Mokola is an area located within Ibadan North Local Government Area of Oyo State Nigeria (NIPOST, 2010). It is bordered to the East by the University College Hospital, to the west by the University of Ibadan, to the north by Agodi and to the south by Jericho. It is a residential and commercial area mostly inhabited by Hausa traders. Malaria is responsible for the greatest morbidity in the community as could be seen from the health record in the maternity centre in the community. This has led to several studies being carried out on the knowledge and perception of malaria among women in the community, but none has been carried out yet on the 
knowledge and perception of malaria among men in the community.

\section{Study Population}

Target population consist of married men living in Mokola community.

\section{Sample Size Determination}

The sample size for this study was determined by using the formula below:

$$
N=\frac{z^{2} p q}{d^{2}}
$$

(Bassey and Izah, 2017)

$z=$ Standard normal deviation set at 1.96 normal interval

$p=$ prevalence of malaria in Nigeria (27\%) (WHO, 2017)

$q=$ proportions that does not have the characteristics being investigated $(\mathrm{q}=1-\mathrm{p}), \mathrm{q}=1-0.27=0.73$

$d=$ Level of significance set at 0.05 (precision set at $5 \%$ )

$n=\frac{(1.96) 2 \times 0.27 \times 0.73}{0.05 \times 0.05}$

$n=302$

Ten percent (10\%) of the calculated sample size (30) was added for non-response to make it 332 in order to address the issue of incomplete responses.

\section{Sampling Technique}

A three-stage sampling technique was used to recruit study respondents.

Stage one: The community was stratified into the Hausa and Okesu axis. The Hausa axis had Hausa people and the Okesu axis had Yoruba people. The houses with married men in the Hausa axis were then enumerated.

Stage two: The houses with married men used for the study were determined using systematic random sampling. A sampling interval was derived by dividing the total sample size by the number of houses with married men in the Hausa axis of the community. The first house was determined by assigning numbers 1-10 and the interviewer selected the closest of the houses. The sampling interval was then used to select subsequent houses.

Stage three: When a particular household had more than one married man, balloting was used to select the married man to be involved in the study. This was done while putting into cognizance the exclusion criteria.

\section{Inclusion and Exclusion Criteria}

Married men who are Hausa and living within Mokola community.

\section{Exclusion Criteria}

- Married men who are living in the community.

- Sick married Hausa men were also not involved in the study.

\section{Instrument for Data Collection}

A semi- structured, pre-tested, interviewer administered questionnaire was used to collect information from the respondents. This was developed based on the set objectives, review of literature and guidance of the research supervisor.
The questionnaire consisted of four (4) sections. Section A documents the socio-demographic characteristics of study respondents; Section B explored the general knowledge of respondents on malaria; its causes, mode of transmission, management and prevention. Section $C$ sets to determine the perception of respondents on malaria. Section $\mathrm{D}$ explored the preventive practices employed for malaria control by the respondents.

Knowledge, perception and preventive practices were measured on a 22-point, 26-point and 14-point scales, respectively. Knowledge scores of $1-13$ and scores $>13$ were categorized as poor and good, respectively. Perception scores of 0-16 and scores $>16$ were categorized as poor and good, respectively. Preventive practice scores of $0-8$ and scores $>8$ were categorized as poor and good, respectively. The questionnaire was translated to Hausa language and back to English for it to retain its original meaning.

\section{Procedure for Data Collection}

Four research assistants with Bachelor's degree and experience in data collection were recruited and trained for collection of data. The training featured; providing an overview of the research objectives, obtaining informed consent, data collection procedure, how to review questionnaire to ensure completeness and accuracy. Issues relating to privacy and good interpersonal relationship were also discussed. The criteria for selection of research assistants included; good communication skill, good interpersonal relationship, availability, interest for the research, respect for persons, good knowledge, understanding and ability to speak and read English and Hausa language.

Using the questionnaire, each respondent was interviewed by the researcher with the help of the four (4) trained research assistants after obtaining informed consent through provision of adequate information about the study; on the purpose, the risk involved, the benefit and the requirement of the respondents. Data were collected in the selected houses of respondents after obtaining informed consent. The copies of the questionnaire were retrieved immediately after completion and checked if they were correctly filled.

\section{Validity}

Validity of the instrument was ensured through consultation of relevant literature. Face validity was ensured by making sure that the variables in the theoretical framework and also the study objectives are well represented in the instrument. The questionnaire was subjected to critical review by the research supervisor and colleagues to ascertain its quality. Validity was also ensured by using simple language and translated to Hausa language and also by ensuring clarity of questions in the research instrument.

\section{Reliability}

To ensure reliability, the instrument was pre-tested among similar study participants in Sasa community in Akinyele LGA which has similar socio-demographic characteristics. The data obtained was analyzed to obtain Cronbach's alpha as reliability coefficient. A reliability coefficient of 0.69 was obtained and considered reliable. Few editing was done to few question items in the questionnaire like the question "Is malaria a 
communicable disease?" to "How is malaria transmitted? This was done to ensure that the questions were clear and simple enough for respondents to understand and to also determine consistency of the questions.

\section{Data Management, Analysis and Presentation}

Data obtained were sorted, cleaned for errors, coded and entered. Data collected were analyzed using Statistical Package for Social Sciences (SPSS) version 22 software after being serially numbered for easy identification, control, analysis and recall purposes in case of any problem. Descriptive statistics such as percentages and mean were used to summarize variables such as demographics and factors influencing knowledge, perception and practice.

\section{Ethical Considerations}

The study followed the basic ethical principles guiding research involving human respondents. Ethical approval was obtained from the Oyo State Research Ethics Review Committee to ensure the proposed study has met all the principles and National guidelines in research involving human respondents (AD 13/479/1466). An informed consent was sought from each respondent through appended signature on the form after adequate provision of information. All identifiers were removed from the questionnaire and confidentiality was ensured through protection of data collected from respondents.

\section{Confidentiality}

In order to guarantee respondents of confidentiality of the information that was given, names, phone numbers or addresses of respondents were not requested, only identification numbers were assigned to the questionnaires for proper recording. The data of all respondents were identified by the codes. The printed data was kept safe in secured office lockers during and after the study and electronic data was stored in a password-protected computer system.

\section{Beneficence}

The outcome of the research shall be of benefit not only to the researcher but also to the respondents and the entire members of Sabo community and beyond.

\section{Non-maleficence}

The research was not invasive in nature; therefore collection of invasive materials was not required. Hence, safety of the participants is guaranteed.

\section{Voluntariness}

The respondents had the full details concerning the research before they took part in it and they were informed of their full rights to withdraw at any stage of the study.

\section{Informed consent}

The purpose of the research was adequately communicated to the respondents.

\section{Feedback}

The final outcome of this study and recommendations would be communicated to all stakeholders at the conclusion of the study.
Table 1. Sociodemographic characteristics of respondents $(\mathrm{N}=302)$

\begin{tabular}{lcc}
\hline Variable & Frequency & Percent (\%) \\
\hline Below 35 years & 127 & 42.1 \\
35 - 44 years & 125 & 41.4 \\
45 - 54 years & 49 & 16.2 \\
55 years or more & 1 & 0.3 \\
Occupation & & \\
$\quad$ Businessman & 295 & 97.7 \\
$\quad$ Civil servant & 7 & 2.3 \\
Monthly Income & & \\
Below \#30,000 & 44 & 14.6 \\
\#30,000 - \#75,000 & 169 & 56.0 \\
\#76,000 - \#100,000 & 32 & 10.6 \\
Above \#100,000 & 57 & 18.8 \\
Educational Qualification & & \\
Qur'anic & 31 & 10.3 \\
Primary school & 8 & 2.6 \\
Secondary school & 175 & 57.9 \\
Undergraduate degree & 88 & 29.2 \\
\hline
\end{tabular}

\section{Inducements}

No fees were paid to any of the respondents.

\section{RESULT}

\section{Respondents Socio-demographic Characteristics}

The results of the respondents' socio-demographic characteristics are presented in this section. The key sociodemographic variables measured were respondents' age, religion, ethnic group, family structure, occupation, income, and educational qualification, number of children, house ownership, and type of sanitary system. A greater proportion of the men who participated in the study were below the age of 35 years and where all of the Hausa ethnic group. Traders accounted for $97.7 \%$ participants of the study participants, the majority of whose monthly income ranges between N30,000N75,000. Those with secondary education accounted for the majority (57.9\%) while those with primary accounted for the minority (2.6\%) with those with qur'anic education accounting for $10.3 \%$ and tertiary education accounting for $29.1 \%$ (Table 1).

\section{Respondents' Household and Environmental Characteristics}

Monogamy was practised by $75.5 \%$ of the respondents with $73.2 \%$ having less than 5 children. Most of the study participants had secondary education. Respondents who had their houses accounted for $57.0 \%$. Most (98.0\%) of these houses have window nets. Only $1.0 \%$ of the houses have a water system toilet with $84.4 \%$ having open gutters around them (Table 2).

\section{Respondents' Personal Experiences on Malaria}

Respondents who had been screened for malaria before accounted for $97.4 \%$ with $42.4 \%$ of respondents reporting weakness of joint and other parts of the body as symptoms and $18.5 \%$ reporting loss of appetite as symptoms. These symptoms prompted the urge for screening with $99.7 \%$ of respondents receiving treatment. Respondents who had 
Table 2. Respondents' household and environmental characteristics $(\mathrm{N}=302)$

\begin{tabular}{lcc}
\hline Family Structure & Frequency & Percent (\%) \\
\hline Monogamy & 228 & 75.5 \\
$\quad$ Polygyny & 74 & 24.5 \\
Number of Children & & \\
$\quad$ < children & 221 & 73.2 \\
5 - 9 children & 61 & 20.2 \\
$\quad$ 10 or more children & 20 & 6.6 \\
House Ownership & & \\
$\quad$ Yes & 172 & 57.0 \\
$\quad$ No & 130 & 43.0 \\
Number of rooms in house & & \\
$\quad$ One room & 6 & 2.0 \\
$\quad$ Two rooms & 85 & 28.1 \\
$\quad$ Three rooms & 117 & 38.7 \\
$\quad$ Four rooms & 39 & 12.9 \\
Five rooms & 30 & 9.9 \\
$\quad$ More than 5 rooms & 25 & 8.4 \\
\hline
\end{tabular}

Table 3. Personal history on malaria $(\mathrm{N}=302)$

\begin{tabular}{|c|c|c|}
\hline Variable & Frequency & Percent (\%) \\
\hline \multicolumn{3}{|c|}{ Ever being screened for malaria before } \\
\hline Yes & 294 & 97.4 \\
\hline No & 8 & 2.6 \\
\hline \multicolumn{3}{|c|}{ Ever being treated for malaria before } \\
\hline Yes & 301 & 99.7 \\
\hline No & 1 & 0.3 \\
\hline \multicolumn{3}{|l|}{ Last time you had malaria } \\
\hline Can't remember & 5 & 1.7 \\
\hline Currently & 23 & 7.6 \\
\hline Less than 1 month & 143 & 47.4 \\
\hline $1-6$ months & 64 & 21.1 \\
\hline $7-12$ months & 28 & 9.3 \\
\hline More than 12 months & 39 & 12.9 \\
\hline \multicolumn{3}{|c|}{ The last time a family member had malaria } \\
\hline Can't remember & 11 & 3.6 \\
\hline Currently & 62 & 24.5 \\
\hline Less than 1 month & 155 & 51.3 \\
\hline $1-6$ months & 46 & 16.0 \\
\hline More than 12 months & 14 & 4.6 \\
\hline \multicolumn{3}{|l|}{ Observed signs of malaria } \\
\hline Swollen lips & 2 & 0.7 \\
\hline Fever \& yellow urine & 10 & 3.3 \\
\hline Vomiting & 12 & 4.0 \\
\hline Shivering & 19 & 6.1 \\
\hline Headache & 29 & 9.0 \\
\hline High temperature & 48 & 15.9 \\
\hline Loss of appetite & 56 & 18.5 \\
\hline $\begin{array}{l}\text { Weakness of the joints \& other } \\
\text { parts of the body }\end{array}$ & 128 & 42.5 \\
\hline
\end{tabular}

malaria less than a month ago accounted for $47.4 \%$ with $51.3 \%$ of respondents saying a member of their household also had malaria less than a month ago too (Table 3).

\section{Knowledge of Participants on Malaria}

The majority of respondents (76.2\%) defined malaria as a disease caused by mosquito bites with $4.3 \%$ and $4.3 \%$ of respondents simply defining malaria as a disease that causes joint pain and also a disease that leads to shivering and vomiting, respectively (Table 4). Most of the respondents (94.4\%) knew that malaria was caused by mosquito bites with
Table 4. Knowledge on definition of malaria among respondents $(\mathrm{N}=302)$

\begin{tabular}{lcc}
\hline Variable & Frequency & Percent (\%) \\
\hline $\begin{array}{l}\text { It is a common or global disease } \\
\text { A condition characterized by body }\end{array}$ & 13 & 4.3 \\
weakness & 4 & 1.3 \\
$\begin{array}{l}\text { A disease emanating from a dirty } \\
\text { environment }\end{array}$ & 2 & 0.7 \\
$\begin{array}{l}\text { Disease caused by mosquito } \\
\text { A disease caused by groundnut }\end{array}$ & 230 & 70.2 \\
$\begin{array}{l}\text { consumption } \\
\text { A condition leading to headache and hot }\end{array}$ & 2 & 0.7 \\
temperature & 42 & 12.1 \\
$\begin{array}{l}\text { A hereditary disease } \\
\text { A disease caused by weather }\end{array}$ & 2 & 0.7 \\
$\begin{array}{l}\text { A health condition leading to joint pain } \\
\text { Disease characterized with loss of }\end{array}$ & 13 & 0.7 \\
appetite & 2 & 0.3 \\
A condition in which one is shivering or & 13 & 0.7 \\
vomiting & & \\
\hline
\end{tabular}

Table 5. Knowledge of causes of malaria among respondents $(\mathrm{N}=302)$

\begin{tabular}{lcc}
\hline Variable & Frequency & Percent (\%) \\
\hline Caused by God & 6 & 2.0 \\
Caused by destiny & 2 & 0.7 \\
Caused by dirty environment & 2 & 0.7 \\
Caused as a result consuming & 6 & 2.0 \\
groundnut oil & & \\
Caused by hereditary conditions & 2 & 0.7 \\
Caused by mosquito bites & 285 & 93.9 \\
\hline
\end{tabular}

$2.0 \%$ of them attributing the cause of the disease to God (Table 5).

Most respondents (22.2\%) obtained information about malaria from the electronic media (radio and television) with $1.0 \%$ obtaining information about the disease from print media. The hospital also served as a source of information for $15.6 \%$ of respondents with $2.6 \%$ obtaining information about the disease from health workers and $0.3 \%$ obtaining information about the disease from herb sellers. Friends and colleagues in trade also served as the source of information on malaria to $7.3 \%$ of respondents (Table 6).

Most of the respondents knew that malaria is transmitted through mosquito bites with $39.0 \%$ knowing that insecticidetreated nets (ITN) could be used to prevent the transmission of malaria and $37.5 \%$ knowing that indoor residual spray (IRS) could be used to prevent malaria transmission (Table 7). Knowledge of the use of prophylaxis to prevent malaria transmission was reported by $22.5 \%$ of respondents with $0.6 \%$ knowing the use of the orange pill for prevention of malaria transmission. Cleaning gutters and clearing stagnant water was reported by $35.0 \%$ and $11.9 \%$ of respondents, respectively as a means of preventing malaria transmission (Table 8).

The majority of respondents (61.9\%) knew joint weakness/pain as a symptom of malaria with $31.9 \%$ knowing the loss of appetite as a symptom and $27.5 \%$ knowing headache as a symptom of malaria (Table 9 ).

Most (99.3\%) respondents knew that drugs are used to treat malaria with $62.5 \%$ of respondents acknowledging buying 
Table 6. Knowledge of sources of information on malaria among respondents $(\mathrm{N}=302)$

\begin{tabular}{lcc}
\hline Variable & Frequency & Percent (\%) \\
\hline Through awareness and campaigns & 6 & 2.0 \\
From health workers and practitioners & 8 & 2.6 \\
From a herb seller & 1 & 0.3 \\
From the hospital & 47 & 15.6 \\
Through the electronic media (Radio & 67 & 22.2 \\
\& Television) & & \\
From friends and colleagues & 22 & 7.3 \\
Through print media (Newspaper) & 3 & 1.0 \\
\hline
\end{tabular}

Table 7. Knowledge of respondents on how malaria is transmitted $(\mathrm{N}=302)$

\begin{tabular}{lcc}
\hline Variable & Frequency & Percent (\%) \\
\hline Through mosquito bites & 302 & 100.0 \\
\hline
\end{tabular}

Table 8. Knowledge of respondents on how malaria transmission can be prevented $(\mathrm{N}=302)$

\begin{tabular}{lcc}
\hline Variable & Frequency & Percent (\%) \\
\hline Cleaning the environment & 26 & 8.8 \\
Cleaning the gutters & 106 & 35.0 \\
Cleaning of stagnant water & 36 & 11.9 \\
Cleaning of toilets & 9 & 3.1 \\
Using insecticide repellant cream & 2 & 0.6 \\
Going to the hospital & 23 & 7.5 \\
Using IRS (Indoor Residual Spray) & 113 & 37.5 \\
Using ITN (Insecticide Treated Nets) & 117 & 39 \\
Using the mosquito coil & 19 & 6.3 \\
Using orange pill & 2 & 0.6 \\
Using prophylaxis & 68 & 22.5 \\
Using windows with net & 9 & 3.1 \\
\hline
\end{tabular}

Table 9. Knowledge of respondents on symptoms of malaria $(\mathrm{N}=302)$

\begin{tabular}{lcc}
\hline Variable & Frequency & Percent (\%) \\
\hline Feeling feverish & 4 & 1.3 \\
Feeling the need to take drugs or visit & 4 & 1.2 \\
the hospital & & \\
Headache & 83 & 27.5 \\
Hot body temperature & 81 & 26.9 \\
Joint weakness and pain & 187 & 61.9 \\
Loss of appetite & 96 & 31.9 \\
Shivering & 53 & 17.5 \\
Swollen lips & 2 & 0.6 \\
Vomiting & 30 & 10.0 \\
Yellowing of the eyes & 8 & 2.5 \\
Yellowing of urine & 21 & 6.9 \\
\hline
\end{tabular}

drugs as one of the roles men should play in the treatment of malaria in their households (Table 11).

Many respondents acknowledged that clearing of gutters and the surrounding environment was the best way to protect themselves and their households from malaria with $34.4 \%$ acknowledging the use of IRS and $26.6 \%$ use of ITN as ways of protecting themselves and their households from malaria (Table 12).

\section{Respondents Perception on Malaria}

Table 14 shows the perception of respondents on malaria. Respondents who agreed that malaria is not as serious as portrayed accounted for $8.6 \%$. Respondents who were of the
Table 10. Knowledge of respondents on treatment of malaria $(\mathrm{N}=302)$

\begin{tabular}{lcc}
\hline Variable & Frequency & Percent (\%) \\
\hline Use of drugs & 300 & 99.3 \\
Cleaning gutter and stagnant water & 4 & 1.2 \\
Visiting hospital & 15 & 5.0 \\
\hline
\end{tabular}

Table 11. Knowledge of respondents on roles men should play in the treatment of malaria $(\mathrm{N}=302)$

\begin{tabular}{lcc}
\hline Variable & Frequency & Percent (\%) \\
\hline Buying malaria drugs for the ill person & 189 & 62.5 \\
Cleaning the environment and gutters & 74 & 24.4 \\
Providing IRS & 32 & 10.6 \\
Providing ITN & 15 & 5.0 \\
Providing mosquito nets & 9 & 3.1 \\
Taking ill persons to the hospital & 185 & 61.3 \\
\hline
\end{tabular}

Table 12. Knowledge of respondents on ways to prevent family from malaria attack $(\mathrm{N}=302)$

\begin{tabular}{lcc}
\hline Variable & Frequency & Percent (\%) \\
\hline Cleaning gutter and environment & 145 & 48.1 \\
Clearing the bushes & 4 & 1.3 \\
Clearing stagnant water around & 25 & 8.1 \\
vicinity & & \\
Covering food & 4 & 1.3 \\
Drinking clean water & 13 & 4.4 \\
Eating clean food & 11 & 3.8 \\
Taking prophylaxis & 53 & 17.5 \\
Use of first aid & 2 & 0.6 \\
Using IRS & 104 & 34.4 \\
Using ITN & 79 & 26.3 \\
Using mosquito coil & 19 & 6.3 \\
Use mosquito net & 13 & 4.4 \\
\hline
\end{tabular}

Table 13. Respondents knowledge on malaria ( $\mathrm{N}=302)$

\begin{tabular}{ccc}
\hline Knowledge grade & Frequency & Percent (\%) \\
\hline Poor $(<13)$ & 33 & 10.9 \\
Good $(\geqslant 13)$ & 269 & 89.1 \\
Total & 302 & \\
\hline
\end{tabular}

perception that malaria could result in eventual death accounted for $1.0 \%$. Most of the respondents believed that death can only be caused by God. Respondents who were of the perception that only women and children could be affected with malaria accounted for $7.6 \%$ with $80.1 \%$ of the view that men could also be affected by the disease. Most of those that believed that only women and children could be infected with malaria did so because women and children were always at home and had more regular contact with water (Table 14).

Respondents who were of the perception that prolonged standing in the sun can cause malaria accounted for $84.1 \%$, with $85.4 \%$ of the perception that tiredness could cause the disease and $66.9 \%$ of respondents of the perception that rainfall could cause malaria. Only $9.9 \%$ had the correct perception that malaria is caused when someone was beaten by an infected anopheles mosquito. Most of the respondents' associated rainfall with malaria because they believed water was a factor in malaria transmission (Table 14).

Respondents who had the perception that malaria could not be prevented accounted for $3.0 \%$ with $5.0 \%$ of them believing that men had no role to even play in the prevention 
Table 14. Respondents perception on Malaria ( $\mathrm{N}=302)$

\begin{tabular}{|c|c|c|c|c|}
\hline \multirow[t]{2}{*}{ Variable } & \multicolumn{2}{|c|}{ Agree } & \multicolumn{2}{|c|}{ Disagree } \\
\hline & Frequency & Percent (\%) & Frequency & Percent (\%) \\
\hline \multicolumn{5}{|l|}{ Perception on seriousness of malaria } \\
\hline Malaria is not as serious as portrayed & 26 & 8.6 & 276 & 91.4 \\
\hline Malaria if not treated can result to death & 3 & 1.0 & 299 & 99.0 \\
\hline \multicolumn{5}{|l|}{ Perception on causes of malaria } \\
\hline Malaria is as a result of spiritual attack & 121 & 40.1 & 181 & 59.9 \\
\hline Malaria occurs when rain falls on a person & 202 & 66.9 & 100 & 33.1 \\
\hline Hunger can be a major cause of malaria & 157 & 52.0 & 145 & 48.0 \\
\hline Tiredness can cause malaria & 258 & 85.4 & 44 & 14.6 \\
\hline Malaria only occurs when someone is beaten by mosquito & 30 & 9.9 & 272 & 90.1 \\
\hline Bathing with hot water can cause malaria & 55 & 18.2 & 247 & 81.8 \\
\hline Eating too much palm oil can cause malaria & 55 & 18.2 & 247 & 81.8 \\
\hline Long-standing in the sun can cause malaria & 254 & 84.1 & 48 & 15.9 \\
\hline \multicolumn{5}{|l|}{ Perception on susceptibility of malaria } \\
\hline Malaria affects only women and children & 23 & 7.6 & 279 & 92.4 \\
\hline Men cannot be infected with malaria & 60 & 19.9 & 242 & 80.1 \\
\hline \multicolumn{5}{|l|}{ Perception on preventive practices towards malaria } \\
\hline Indoor residual spray of insecticide can be used to prevent malaria & 19 & 6.3 & 283 & 93.7 \\
\hline Screened windows can be used to prevent malaria & 45 & 14.9 & 257 & 85.1 \\
\hline Malaria cannot be prevented & 9 & 3.0 & 293 & 97.0 \\
\hline Men do not have any role in the prevention of malaria & 15 & 5.0 & 287 & 95.0 \\
\hline Insecticide-treated nets were designed to beautify the house & 6 & 2.0 & 296 & 98.0 \\
\hline Insecticide-treated nets are meant for keeping someone warm & 11 & 3.6 & 291 & 96.4 \\
\hline Removal of stagnant water from the surroundings can prevent malaria & 4 & 1.3 & 298 & 98.7 \\
\hline Insecticide-treated net cannot prevent transmission of malaria & 67 & 22.2 & 235 & 77.8 \\
\hline Skin applied chemical repellents can be used to prevent malaria & 152 & 50.3 & 150 & 49.7 \\
\hline Repellant coils cannot be used to prevent malaria & 188 & 62.3 & 114 & 37.7 \\
\hline Insecticide-treated net were manufactured by white people to kill Africans & 35 & 11.6 & 267 & 88.4 \\
\hline Proper clothing that covers all the body can be used to prevent malaria & 172 & 57.0 & 130 & 43.0 \\
\hline Only women and children can sleep under insecticide-treated net & 45 & 14.9 & 257 & 85.1 \\
\hline Only pregnant women should sleep under insecticide-treated net & 41 & 13.6 & 261 & 86.4 \\
\hline
\end{tabular}

Table 15. Respondents perception on malaria ( $\mathrm{N}=302)$

\begin{tabular}{ccc}
\hline Perception grade & Frequency & Percent (\%) \\
\hline Poor $(<16)$ & 9 & 3.0 \\
Good $(\geqslant 16)$ & 293 & 97.0 \\
Total & 302 & \\
\hline
\end{tabular}

of malaria in the first place. Respondents who had the perception that insecticide-treated nets (ITN) could be used to prevent malaria accounted for $77.8 \%$ with $14.9 \%$ of them believing that only women and children could sleep under ITN and $13.6 \%$ believing that only pregnant women should sleep under ITN. Respondents who did not believe that indoor residual spray (IRS) could be used to prevent malaria accounted for $6.3 \%$, with $11.6 \%$ of the respondents of the perception that IRS was manufactured by the white people to kill Africans. Most of the respondents who believed malaria cannot be prevented based their opinion on the fact that it is only God that protects his creatures against harm (Table 14).

Overall, 3.0\% of respondents had a poor perception of malaria and $97.0 \%$ had a good perception of the disease (Table 15).

Preventive Practices against Malaria Adopted by Respondents in their Households

Respondents who practised the use of insecticide repellant creams as prevention against malaria for their families accounted for $62.9 \%$ while $77.5 \%$ of respondents practice the use of herbal concoction as prevention against malaria for their families (Table 16).
Respondents who used ITN as prevention against malaria for their families accounted for $80.8 \%$ and $95.7 \%$ used IRS for their families every night before sleeping (Table 16).

Overall, $21.5 \%$ of respondents practised wrong preventive practices against malaria while $78.5 \%$ of respondents practised the right preventive practice against the disease (Table 17).

Factors Inhibiting Adoption of Preventive Practices against Malaria by Married Men in their Households

Lack of money accounted for the highest (74.8\%) hindering factor towards the adoption of preventive practices against malaria by most respondents in their households with cultural belief accounting for the least 3.0\% (Figure 1).

Respondents who believed that women should be the ones concerned about malaria accounted for $58.9 \%$ and $15.2 \%$ of respondents believe that men should be less concerned about the disease and therefore do not adopt any preventive practices in their households with $25.5 \%$ of respondents complaining of lack of time as a hindering factor towards the adoption of preventive practices since they were businessmen and spent little time at home due to business activities (Figure 1).

Respondents who complained of the attitudes of health workers as a hindering factor for them towards the adoption of preventive practices in their households accounted for $39.7 \%$. Most of them complained about the long waiting time in most public hospitals and how health workers addressed them in the presence of their spouses and children (Figure 1). 
Table 16. Preventive practices against malaria $(\mathrm{N}=302)$

\begin{tabular}{|c|c|c|c|c|}
\hline \multirow{2}{*}{ Variable } & \multicolumn{2}{|c|}{ Not Done } & \multicolumn{2}{|c|}{ Done } \\
\hline & Frequency & Percent (\%) & Frequency & Percent (\%) \\
\hline Use of insecticide-treated net & 58 & 19.2 & 244 & 80.8 \\
\hline Spraying of insecticide before sleeping (IRS) & 13 & 4.3 & 289 & 95.7 \\
\hline Not storing stagnant water & 5 & 1.7 & 297 & 98.3 \\
\hline Regular clearing of drainage surrounding the house & 6 & 2.0 & 296 & 98.0 \\
\hline Regular clearing of surrounding bushes & 7 & 2.3 & 295 & 97.7 \\
\hline Wearing of proper clothing that covers all the body & 183 & 60.6 & 119 & 39.4 \\
\hline Regular use of insecticide repellant cream on the body & 112 & 37.1 & 190 & 62.9 \\
\hline Regular keeping of a clean environment & 15 & 5.0 & 287 & 95.0 \\
\hline Regular proper waste disposal & 24 & 7.9 & 278 & 92.1 \\
\hline Taking of herbal concoction that is believed can cure malaria (D70) & 234 & 77.5 & 68 & 22.5 \\
\hline Regular burying /destruction of waste cans & 58 & 19.2 & 244 & 80.8 \\
\hline Avoid eating sweet foods (D72) & 66 & 21.9 & 236 & 78.1 \\
\hline Regular use of mosquito coil & 123 & 40.7 & 179 & 59.3 \\
\hline Regular use of prophylaxis & 106 & 35.1 & 196 & 64.9 \\
\hline
\end{tabular}

Table 17. Respondents' preventive practices against malaria $(\mathrm{N}=302)$

\begin{tabular}{ccc}
\hline Knowledge grade & Frequency & Percentage (\%) \\
\hline Bad $(<8)$ & 65 & 21.5 \\
Good $(\geqslant 8)$ & 237 & 78.5 \\
Total & 302 & \\
\hline
\end{tabular}

Hypothesis 1: Association between level of education and knowledge of malaria

The test of association between level of education and knowledge of malaria showed that only knowledge on symptoms of malaria was associated with the respondents' level of education $(p=0.012)$; the result also revealed that

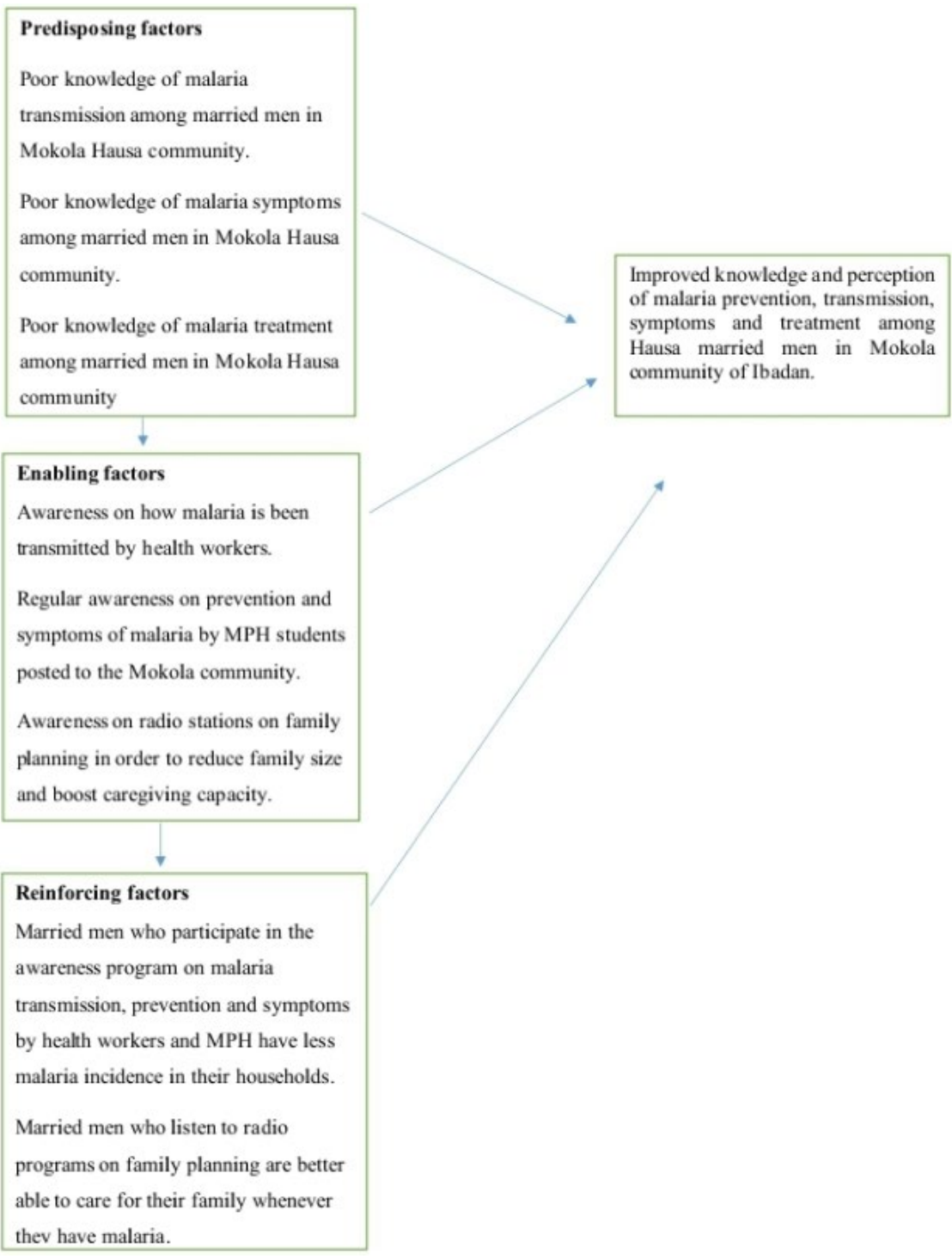

Figure 1. The Precede-model (Green et al., 1980) 
Table 18. Factors inhibiting adoption of preventive practices against malaria by married men in their households

\begin{tabular}{lcc}
\hline Variable & Frequency & Percent (\%) \\
\hline Cultural belief & 9 & 3.0 \\
Religious belief & 25 & 8.3 \\
Men should be less concerned with malaria & 46 & 15.2 \\
Lack of time & 77 & 25.5 \\
Attitude of health workers & 120 & 39.7 \\
Women should be more concerned with malaria & 178 & 58.9 \\
Lack of information & 216 & 71.5 \\
Lack of money & 226 & 74.8 \\
\hline
\end{tabular}

Table 19. Hypothesis $1(\mathrm{~N}=302)$

\begin{tabular}{|c|c|c|c|c|c|c|}
\hline & \multicolumn{4}{|c|}{ Level of Education } & \multirow{3}{*}{\multicolumn{2}{|c|}{$\begin{array}{c}\text { Fishers exert P-value } \\
\text { test } \\
\mathrm{x}^{2} \\
\end{array}$}} \\
\hline & \multirow{2}{*}{\multicolumn{2}{|c|}{$\begin{array}{c}\text { Below Tertiary } \\
\text { Frequency Percent (\%) }\end{array}$}} & \multicolumn{2}{|c|}{ Tertiary } & & \\
\hline & & & Frequency & Percent (\%) & & \\
\hline \multicolumn{7}{|l|}{ Knowledge of causes } \\
\hline Poor knowledge & 212 & 99.1 & 88 & 100.0 & \multirow{2}{*}{0.83} & \multirow{2}{*}{1.00} \\
\hline Good knowledge & 2 & 0.9 & 0 & 0.0 & & \\
\hline \multicolumn{7}{|c|}{ Knowledge of transmission } \\
\hline Poor knowledge & 8 & 3.7 & 0 & & \multirow{2}{*}{3.38} & \multirow{2}{*}{0.110} \\
\hline Good knowledge & 206 & 96.3 & 88 & 100.0 & & \\
\hline \multicolumn{7}{|c|}{ Knowledge of treatment } \\
\hline Poor knowledge & 5 & 2.3 & 0 & & \multirow{2}{*}{2.09} & \multirow{2}{*}{0.326} \\
\hline Good knowledge & 209 & 97.7 & 88 & 100.0 & & \\
\hline \multicolumn{7}{|c|}{ Knowledge of symptoms } \\
\hline Poor knowledge & 24 & 11.2 & 2 & 2.3 & \multirow{2}{*}{6.34} & \multirow{2}{*}{0.012} \\
\hline Good knowledge & 190 & 88.8 & 86 & 97.7 & & \\
\hline \multicolumn{7}{|c|}{ Knowledge of prevention } \\
\hline Poor knowledge & 36 & 16.8 & 14 & 15.9 & \multirow{2}{*}{0.04} & \multirow{2}{*}{1.00} \\
\hline Good knowledge & 178 & 83.2 & 74 & 84.1 & & \\
\hline \multicolumn{7}{|c|}{ Overall knowledge on malaria } \\
\hline Poor knowledge & 24 & 11.2 & 9 & 10.2 & \multirow{2}{*}{0.06} & \multirow{2}{*}{0.803} \\
\hline Good knowledge & 190 & 88.8 & 79 & 89.8 & & \\
\hline
\end{tabular}

while up to $98.0 \%$ of the respondents who had attained tertiary education were rated to have good knowledge on symptoms of malaria, not more than $89.0 \%$ of those with educational level below tertiary had good knowledge.

It was revealed that the level of education of the respondents was not statistically significantly associated with knowledge on causes of malaria $(p=1.00)$, knowledge on transmission of malaria $(p=0.110)$, knowledge on treatment of malaria $(\mathrm{p}=0.326)$, knowledge on prevention of malaria $(p$ $=1.00)$, and the overall knowledge on malaria $(p=0.803)$.

Hypothesis 2: Association between level of education and perception of malaria

Test of association between level of education and perception of malaria revealed that perception of the respondents on causes of malaria was significantly associated with their level of education ( $p=0.003$ ); while about $46.0 \%$ of those who attained below tertiary education had a good perception on the causes of malaria, only about a quarter (27.0\%) of those with tertiary education had a good perception on the causes of malaria.

The respondents' level of education was not associated with their perception on seriousness of malaria $(p=0.392)$, perception on susceptibility of malaria $(p=0.112)$, perception on preventive practices of malaria $(p=0.676)$ and overall perception on malaria $(\mathrm{p}=1.00)$.
Hypothesis 3: Association between knowledge and perception of malaria

The test of association between respondents' knowledge and perception on malaria revealed that knowledge and perception were significantly associated $(p<0.001)$; all of the respondents with good knowledge also had a good perception of malaria (100.0\%), while not up to three-quarter (73.0\%) of those with poor knowledge had a good perception on malaria.

Hypothesis 4: Association between knowledge and preventive practices against malaria

The test of hypothesis to determine the association between knowledge and the preventive practices of respondents revealed a statistically significant association exists between knowledge level and preventive practices $(\mathrm{p}=$ 0.028 ); noteworthy from the result was that more than threequarters (80.0\%) of those with good knowledge were rated to also have a good practice level of the preventive measures, while below two-thirds of those with poor knowledge (63.0\%) had a good preventive practice level.

\section{DISCUSSION, CONCLUSION AND RECOMMENDATIONS}

\section{Discussion of Findings}

All the respondents in the study were of the Hausa ethnic group who practised Islamic faith since they are of the 
Table 20. Hypothesis $2(\mathrm{~N}=302)$

\begin{tabular}{|c|c|c|c|c|c|c|}
\hline \multirow[t]{3}{*}{ Variable } & \multicolumn{4}{|c|}{ Level of Education } & \multirow{3}{*}{\multicolumn{2}{|c|}{$\begin{array}{c}\text { Fishers exert } P \text { - test value } \\
\text { test } \\
x^{2} \\
\end{array}$}} \\
\hline & \multicolumn{2}{|c|}{ Below Tertiary } & \multicolumn{2}{|c|}{ Tertiary } & & \\
\hline & Frequency & Percent (\%) & Frequency & Percent (\%) & & \\
\hline \multicolumn{7}{|c|}{ Perception of seriousness of malaria } \\
\hline Poor perception & 22 & 10.3 & 6 & 6.8 & \multirow{2}{*}{0.89} & \multirow{2}{*}{0.392} \\
\hline Good perception & 192 & 89.7 & 82 & 93.2 & & \\
\hline \multicolumn{7}{|c|}{ Perception of causes of malaria } \\
\hline Poor perception & 115 & 53.7 & 64 & 72.7 & \multirow{2}{*}{9.31} & \multirow{2}{*}{0.003} \\
\hline Good perception & 99 & 46.3 & 24 & 27.3 & & \\
\hline \multicolumn{7}{|c|}{ Perception of susceptibility of malaria } \\
\hline Poor perception & 49 & 22.9 & 13 & 14.8 & \multirow{2}{*}{2.52} & \multirow{2}{*}{0.112} \\
\hline Good perception & 165 & 77.1 & 75 & 85.2 & & \\
\hline \multicolumn{7}{|c|}{ Perception of preventive practices of malaria } \\
\hline Poor perception & 5 & 2.3 & 1 & 1.1 & \multirow{2}{*}{0.46} & \multirow{2}{*}{0.676} \\
\hline Good perception & 209 & 97.7 & 87 & 98.9 & & \\
\hline \multicolumn{7}{|c|}{ Overall perception of malaria } \\
\hline Poor perception & 7 & 3.3 & 2 & 2.3 & \multirow{2}{*}{0.22} & \multirow{2}{*}{1.00} \\
\hline Good perception & 207 & 96.7 & 86 & 97.7 & & \\
\hline
\end{tabular}

Table 21. Hypothesis $3(\mathrm{~N}=302)$

\begin{tabular}{|c|c|c|c|c|}
\hline \multirow[t]{2}{*}{ Variable } & \multicolumn{2}{|c|}{ Overall perception on malaria } & \multirow{2}{*}{$\begin{array}{r}\text { Fishers exert } \\
\text { test } \\
\mathbf{x}^{2}\end{array}$} & \multirow[t]{2}{*}{ P-value } \\
\hline & $\begin{array}{l}\text { Poor perception } \\
\text { Frequency }(\%)\end{array}$ & $\begin{array}{l}\text { Good perception } \\
\text { Frequency }(\%)\end{array}$ & & \\
\hline \multicolumn{5}{|c|}{ Overall knowledge on malaria } \\
\hline
\end{tabular}

Table 22. Hypothesis $4(\mathrm{~N}=302)$

\begin{tabular}{|c|c|c|c|c|c|c|}
\hline \multirow{2}{*}{ Variables } & & Practice tov & alaria & Fishers e & \multirow[b]{2}{*}{ test } & \multirow[b]{2}{*}{ P-value } \\
\hline & $\begin{array}{r}\text { Bad p } \\
\text { Frequency }\end{array}$ & $\begin{array}{l}\text { ractice } \\
\text { Percent (\%) }\end{array}$ & $\begin{array}{l}\text { Good p } \\
\text { Frequency } 1\end{array}$ & $\begin{array}{l}\text { practice } \\
\text { Percent (\%) }\end{array}$ & & \\
\hline \multicolumn{7}{|c|}{ Overall knowledge on malaria } \\
\hline Poor knowledge & 12 & 36.4 & 21 & 63.6 & \multirow{2}{*}{4.83} & \multirow{2}{*}{0.028} \\
\hline Good knowledge & 53 & 19.7 & 216 & 80.3 & & \\
\hline
\end{tabular}

northern extraction where the predominant ethnic group and religion are Hausa and Islam, respectively. Almost all the houses of the respondents had window nets, the presence of window nets could be due to awareness activities on malaria by MPH students undergoing field practice in the community over the years.

Respondents were mostly businessmen who engaged in a bureau de change activities. Most earned between N30,000N75,000 monthly and had more than 5 children. This could influence the caring capacity of most married men. This is in line with a study by Mavis and Humphrey (2015), who found a statistically significant association between respondents' economic conditions (income earning status) and their malaria prevention and control practices.

Most respondents had reported having malaria before. This could be associated with a wrong perception among men that only women/children should sleep under insecticide-treated nets (ITN). Most of the respondents had been screened for malaria in the past. This could be due to awareness of symptoms of malaria by MPH students in the Mokola community. The majority of respondents reported headaches, high temperature, weakness of joints and other parts of the body as symptoms of malaria. This is similar to a study conducted by Oluyemi and Oluyemi (2017) in South-Westen Nigeria, where the majority of respondents acknowledged symptoms of malaria as persistent headache, high temperature, and shivering.
The last time some of the respondents had malaria was less than a month before this study with many of their family members also having the disease less than a month before this study. Wrong perceptions towards preventive practices for malaria could be responsible for this.

Most respondents had good knowledge of malaria. This is similar to a study conducted by Kimbi et al. (2014) in which most (88\%) respondents had a good level of knowledge of malaria. The high knowledge of malaria among respondents could be attributed to their level of education, regular awareness on malaria on social media, and the awareness activities on malaria by MPH students working in the Mokola community over the years. Knowledge of symptoms of malaria was associated with the level of education of respondents $(\mathrm{p}<0.05)$.

Most respondents obtained information on malaria from the electronic media. This is contrary to a study by Kimbi et al. (2014) in which $74.0 \%$ of the respondents obtained information on malaria from the health facility. This could be because virtually all the respondents in this study had an android mobile phone and some had radio sets from where they obtained the information from. Another reason for this is that the maternity center in Mokola is grossly understaffed with no hospital equipment, prompting most residents in the community to abandon it. 
Cleaning of gutters and draining of stagnant water was reported as a means of preventing malaria transmission by some of the respondents. This is contrary to a study conducted by Usman et al. (2015), in South-Western Nigeria where the use of insecticide-treated nets was found to be the most predominant malaria preventive practice by married men. This could be due to the awareness activity on malaria by MPH students working in the community over the years.

Respondents acknowledged headache, high temperature, weakness of joints, and shivering as symptoms of malaria. This is similar to a study conducted by Oluyemi and Oluyemi (2017) in South-Western Nigeria, where respondents also acknowledged symptoms of malaria as persistence of headache, high temperature, and shivering. This could be attributed to awareness activities on malaria on social media and the awareness activities on malaria by MPH students working in the community over the years.

Most of the respondents had a good perception of malaria. This is contrary to a study carried out among married men by Padonou et al. (2018) in Southern Benin, where it was found that only $9.3 \%$ of respondents had a good perception of malaria. This could be attributed to respondents' knowledge of malaria, level of education of respondents (secondary school level), regular media programs on malaria, and awareness on malaria conducted over years by MPH students in the Mokola community. The knowledge and perception of respondents were significantly associated $(\mathrm{p}<0.05)$, as most respondents who had good knowledge of the disease also had a good perception about the disease. The perception of respondents on the causes of malaria was also associated with their level of education $(\mathrm{p}<0.05)$.

Some of the respondents had the right perception that malaria is caused only if beaten by an infected anopheles mosquito, with others having the erroneous perception that prolonged standing in the sun, tiredness, and being beaten by rainfall could cause the disease. This is similar to a study carried out among married men by Padonou et al. (2018) in Southern Benin, where it was found that $9.4 \%$ of respondents attributed the cause of malaria to prolonged standing in the sun. The difference in respondents' perception towards the cause of malaria could be attributed to their level of education, with those having a secondary level of education having a better perception of malaria compared to those with less than the secondary level of education.

Some of the respondents were of the perception that malaria cannot be prevented at all. This is in line with a study by Abd/El-Gayoum et al. (2009), among married men where $39.5 \%$ of respondents reported no attempt to use any preventive measures. This could be attributed to fact that respondents in this category believed that malaria is caused by God.

Most respondents had good preventive practices against malaria. Again, such practices were informed by respondents' knowledge of malaria, the media, their level of education, and the awareness activities over the years by MPH students in Mokola. This is in line with a study by Mazigo et al. (2010), where preventive practices against malaria were significantly associated with the education level. A statistically significant association exists between knowledge of malaria among respondents and their preventive practices $(\mathrm{p}<0.05)$.

Respondents also used herbal concoctions and other traditional means as preventive measures for themselves and their families. Most of the respondents who used herbal concoction and other traditional means for themselves and their families believed that it was more efficacious, affordable, and accessible than western prophylaxis. This is similar to a study by Kirby et al. (2013) where some of the respondents preferred the use of traditional measures to prevent malaria.

Most respondents complained about lack of money as the most pressing reason preventing them from adopting preventive practices against malaria for themselves and their families. This is in line with a study by Mavis and Humphrey (2015) in which a statistically significant association was established between respondents' economic conditions (employment status and income-earning status) and their malaria prevention and control practices. Malaria preventive practices such as the use of indoor residual spray, use of insecticide repellent cream, use of mosquito coil, and use of prophylaxis all involved money and for that reason were not adopted by most respondents.

Lack of essential medicines in health facilities, lack of health workers/properly trained health workers, and the attitude of health workers, especially those involved in the distribution of insecticide-treated nets (ITN) also discouraged some household heads from even attempting to obtain ITN. This is in line with a study conducted by Diala et al. (2013) which found systems-based challenges which include essential medicine supplies stock-outs, lack of provider knowledge on intermittent preventive treatment of malaria contribute to low malaria intervention uptake.

\section{Conclusion}

The study explored the knowledge and perception of malaria among Hausa married men in the Mokola community of Ibadan, Oyo state. The level of knowledge of malaria among married men in the Mokola community was good. The level of education of respondents, awareness of malaria by MPH students working in the community, and social media have all contributed to improving the knowledge of respondents on malaria.

Factors contributing to the transmission of malaria in the Mokola community include the lack of adoption of malaria preventive practices involving money. Such preventive practices include the use of indoor residual sprays, the use of mosquito coil, and use of prophylaxis. Also, erroneous perceptions such as perceptions that only women and children can sleep under insecticide-treated net contribute significantly to the spread of malaria in the community.

The perception of malaria among respondents is good. The level of knowledge of respondents on malaria influenced their perception of the disease.

Factors such as the level of education of respondents, exposure to social media, cultural and religious beliefs of respondents, economic status of respondents, and awareness on malaria by MPH students working in the Mokola community all influence the knowledge, perception, and preventive practices against malaria by married men. 


\section{Recommendations}

1. Regular awareness of malaria should be carried out in other communities.

2. Health workers distributing insecticide-treated nets should be friendly.

3. Health workers should be trained on malaria preventive practices and treatment to boost uptake and adherence to malaria preventive practices by hospital goers.

4. A similar study should be conducted in communities where MPH students have not carried out intervention in the past.

5. The curriculum of MPH students should encourage community awareness on malaria and other endemic diseases.

6. Malaria preventive drugs and other consumables should be subsidized by the government and made readily available to boost affordability.

Funding: No external funding is received for this article.

Declaration of interest: The author declares no competing interests.

Ethics approval and consent to participate: Not applicable.

Availability of data and materials: All data generated or analyzed during this study are available for sharing when appropriate request is directed to the author.

\section{REFERENCES}

Abd/El-Gayoum, S. M. E., El-Rayah, E., Giha, H. A. and El-Feki, A. E. A. (2009). Knowledge, practices and perceptions which affect acquiring malaria in man-made malarious area in Khartoum State, Sudan. Sudanese Journal of Public Health, 4(1), 199-209.

Adedotun, A. A., Morenikeji, O. A. and Odaibo, A. B. (2010). Knowledge, attitudes and practices about malaria in an urban community in south-western Nigeria. Journal of Vector Borne Diseases, 47(3), 155-159.

Adongo, P. B., Kirkwood, B. and Kendall, C. (2005). How local community knowledge about malaria affects insecticide treated net use in northern Ghana. Tropical Medicine and International Health, 10, 366-367. https://doi.org/10.1111/ j.1365-3156.2005.01361.x

Ahmed, S. M., Haque, R., Haque, U. and Hossain, A. (2009). Knowledge on the transmission, prevention and treatment of malaria among two endemic populations of Bangladesh and their health-seeking. Malaria Journal, 8, 173. https://doi.org/10.1186/1475-2875-8-173

Ajayi, I. O., Falade, C. O., Olley, B. O., Yusuf, B., et al. (2008). A qualitative study of the feasibility and community perception on the effectiveness of artemetherlumefantrine use in the context of home management of malaria in south-west Nigeria. Biomed Central Health Services research, 8, 119. https://doi.org/10.1186/14726963-8-119
Aoade, T. M., Evangeline, A. O. and Arulogun, O. S. (2017). Malaria prevention practices among pregnant women resident in two Nigerian army barracks, Ibadan South Western Nigeria. Journal of Public Health and Epidemiology, 9(4), 92-98. https://doi.org/10.5897/JPHE2017.0918

Appiah-Darkwah, I. and Badu-Nyarko, S. K. (2011). Knowledge of malaria prevention and control in a sub-urban community in Accra, Ghana. International Journal of Tropical Medicine, 6(3), 61-69. https://doi.org/ 10.3923/ijtmed.2011.61.69

Aremu, F. J. and Olugbire, O. O. (2015). Socio-economic characteristics of watermelon marketers in Ibadan Metropolis, Oyo State, Nigeria. Elixir International, 80, 31113-31116.

Ashikeni, M. A., Envuladu, E. A. and Zoakah, A. I. (2013). Perception and practice of malaria prevention and treatment among mothers in Kuje Area Council of the Federal Capital Territory, Abuja, Nigeria. International Journal of Medical and Biomedical Research, 2(3), 213-220. https://doi.org/10.14194/ijmbr.239

Atulomah, E. T., Farotimi, A. A. and Atulomah, N. O. (2014). Knowledge, attitude and practice of malaria prevention among expectant mothers attending ante-natal clinic at OOUTH Sagamu, Ogun State. Acta SATECH, 5(1), 9-25.

Bassey, S. and Izah, S. (2017). Some determinant factors of malaria prevalence in Nigeria. Journal of Mosquito Research, 7(7), 48-58. https://doi.org/10.5376/jmr.2017.07.0007

Campbell, T. H., McDaniel, S. H. and Cole-Kelly, K. (2002). Family issues in health care. Family Medicine Principles and Practices, 6, 24. https://doi.org/10.1007/978-0-387-217444 _ 4

Chourasia, M. K., Abraham, V. J. and John, J. (2014). Household training vs. mass campaigns: A better method of health communication for preventing malaria. Tropical Doctor, 44, 196-200. https://doi.org/10.1177/0049475514545201

Chukwuocha, U. M. (2012). Malaria control in Nigeria. Primary Health Care, 2, 118.

Cotter, C., Sturrock, H. J., Hsiang, M. S., Liu, J. et al. (2013). The changing epidemiology of malaria elimination: New strategies for new challenges. The Lancet, 382(9895), 900911. https://doi.org/10.1016/s0140-6736(13)60310-4

Deressa, W., Ali, A. and Enquoselassie, F. (2003). Knowledge, attitude and practice about Malaria the mosquito and antimalarial drugs in a rural community. Ethiopian Journal of Health Development, 17(2), 99-104. https://doi.org/ 10.4314/ejhd.v17i2.9849

Diala, C. C., Pennas, T., Marin, C. and Belay, K. A. (2013). Perceptions of intermittent preventive treatment of malaria in pregnancy (IPTp) and barriers to adherence in Nasarawa and Cross River States in Nigeria. Malaria Journal, 12(1), 342. https://doi.org/10.1186/1475-2875-12342 
Dlamini, S. V., Liao, C.-W., Dlamini, Z. H., Siphepho, J. S., et al. (2017). Knowledge of human social and behavioral factors essential for the success of community malaria control intervention programs: The case of Lomahasha in Swaziland. Journal of Microbiology, Immunology and Infection, 50(2), 245-253. https://doi.org/10.1016/ j.jmii.2015.05.003

Erhun, W. O., Agbani, E. O. and Adesanya, S. O. (2005). Malaria prevention: knowledge, attitude and practice in A Southwestern Nigerian community. African Journal of Biomedicine and Research, 8, 25-29. https://doi.org/10.4314/ajbr.v8i1.35755

Fawole, O. I. and Onadeko, M. O. (2001). Knowledge and home management of malaria fever by mothers and care givers of under five children. West African Journal of Medicine, 20(2), 152-157.

Fungladda, W. and Butraporn, P. (1992). Malaria-related social and behavioral risk factors in Thailand: a review. Southeast Asian Journal of Tropical Medicine and Public Health, 23, 5762.

Garley, A. E., Ivanovich, E., Eckert, E., Negroustoueva, S. and Ye, Y. (2013). Gender differences in the use of insecticidetreated nets after a universal free distribution campaign in Kano State, Nigeria: Post-campaign survey results. Malaria Journal, 12(1), 1-7. https://doi.org/ 10.1186/1475-2875-12-119

Ibidapo, C. A. (2005). Perception of causes of malaria and treatment-seeking behaviour of nursing mothers in a rural community. Australian Journal of Rural Health, 13(4), 214218. https://doi.org/10.1111/j.1440-1584.2005.00704.x

Iriemenam, N. C., Dosunmu A. O., Oyibo, W. A. and FagbenroBeyioku, A. F. (2011). Knowledge, attitude, perception of malaria and evaluation of malaria parasitaemia among pregnant women attending antenatal care clinic in metropolitan Lagos, Nigeria. Journal of Vector Borne Diseases, 48, 12-17.

Joshi, A. and Banjara, M. R. (2008). Malaria related knowledge, practices and behaviour of people in Nepal. Journal of Vector Borne Diseases, 45, 44-50.

Kimbi, H. K., Sarah, B. N., Judith, L. N., Irene, U. N. S., Julius, A. and Atanga, M. B. S. (2014). Knowledge and perceptions towards malaria prevention among vulnerable groups in the BueaHealth District, Cameroon. Biomed Central Public Health, 14, 883. https://doi.org/10.1186/1471-2458-14-883

Kinung’hi, S. M., Mashauri, F., Mwanga, J. R., Nnko, S. E., et al. (2010). Knowledge, attitudes and practices about malaria among communities: comparing epidemics and nonepidemic prone communities of Muleba District, Northwestern Tanzania. Biomed Central Public Health, 10, 395. https://doi.org/10.1186/1471-2458-10-395

Kirkby, K., Galappaththy, G. N., Kurinczuk, J. J., Rajapakse, S. and Fernando, S. D. (2013). Knowledge, attitudes and practices relevant to malaria elimination amongst resettled populations in a post conflict district of northern Sri Lanka. Transactions of the Royal Society of Tropical and Medical Hygiene, 107, 110-118. https://doi.org/10.1093/ trstmh/trs015
Legesse, Y., Tegegn, A., Belachev, T. and Tushune, K. (2007). Knowledge, attitude and practice about malaria transmission and its preventive measures among households in urban areas of Assosa Zone, Western Ethiopia. Ethiopian Journal of Health and Development, 21, 157. https://doi.org/10.4314/ejhd.v21i2.10044

Makemba, A. M., Winch, P. J., Makame, V. M., Mehl, G. L., Premji, Z. and Minjas, J. N. (1996). Treatment practices for degedege, a locally recognized febrile illness, and implications for strategies to decrease mortality from severe malaria in Bagamoyo District, Tanzania. Tropical Medicine and International Health, 1, 305-313. https://doi.org/10.1111/j.1365-3156.1996.tb00043.x

Mazigo, H. D., Obasy, E., Mauka, W., Manyiri, P., Zinga, M., Kweka, E. J., Mnyone, L. L. and Heukelbach, J. (2010). Knowledge, attitudes, and practices about malaria and it's control in rural northwest Tanzania. Malaria Research and Treatment, 2010, 794261. https://doi.org/10.4061/2010/ 794261

Mboera, L. E. G., Shayo, E. H., Senkoro, K. P., Rumisha, S. F., et al. (2010). Knowledge, perceptions and practices of farming communities on linkages between malaria and agriculture in Mvomero District, Tanzania. Acta Tropica, 113(2), 139144. https://doi.org/10.1016/j.actatropica.2009.10.008

McCombie, S. C. (2002). Self-treatment for malaria: the evidence and methodological issues. Health Policy Plan, 17, 333-344. https://doi.org/10.1093/heapol/17.4.333

Michael, G. C., Aliyu, I. and Bukar, G. (2017). Knowledge of malaria and adherence to its preventive measures among adults attending out-patient clinics of a Nigerian tertiary hospital: Has anything changed? African Journal of Medical and Health Sciences, 16(1), 43-51. https://doi.org/10.4103/ ajmhs.ajmhs_81_16

Munguti, K. J. (1998). Community perceptions and treatment seeking for malaria in Baringo District, Kenya: Implications for disease control. Eastern African Medical Journal, 75, 687-91.

National Bureau of Statistics. Nigeria Poverty Profile Report (2010). Available at: http://www.nigeriastat.gov.ng (Accessed: 30 October 2020).

National Malaria Elimination Programme, National Population Commission, National Bureau of Statistics, ICF (2016). Nigeria Malaria Indicator Survey 2015. Available at: https://dhsprogram.com/pubs/pdf/MIS20/MIS20 (Accessed: 30 October 2020).

National Population Commission (2014). Nigeria Demographic and Health Survey (NDHS), 2013. Available at: https://dhsprogram.com/pubs/pdf/fr293/fr293 (Accessed: 30 October 2020).

Ndibuagu, E. O., Omotowo, B. I. and Okafor, I. I. (2017). Effects of formal education on malaria knowledge among residents of a rural community in Enugu state, Southeast Nigeria. Medico Research Chronicals, 4(1), 142-150.

Oguonu, T., Okafor, H. U. and Obu, H. A. (2005). Care giver's knowledge, attitude and practice on childhood malaria and treatment in urban and rural communities in Enugu, South-east Nigeria. Public Health, 119(5), 409-414. https://doi.org/10.1016/j.puhe.2004.05.008 
Okwa, O. O., Soremekun, B. M., Adeseko, O. and Raheem, A. M. (2012). Artisans and traders knowledge, attitude and practices of malaria control in selected areas of Lagos, Nigeria. Global Advanced Research Journal of Medicine and Medical Science, 1(3), 68-74.

Oladimeji, K. E., Tsoka-Gwegweni, J. M., Gengiah, S., Daftary, A. and Naidoo, K. (2018). Barriers to effective uptake of malaria prevention interventions in Ibadan, South West Nigeria: a qualitative study. International Journal of Community Medicine and Public Health, 5(4), 1304-1310. https://doi.org/10.18203/2394-6040.ijcmph20181066

Oluyemi, O. F. and Oluyemi, A. K. (2017). The Study on the Awareness, Knowledge and Perception of Malaria among Selected Secondary School Students in Akure Metropolis, Nigeria. The Open Public Health Journal, l(10), 1-6. https://doi.org/10.2174/1874944501710010001

Onwujekwe, O., Obikeze, E., Uzochukwu, B., Okoronkwo, I. and Onwujekwe, O. C. (2010). Improving quality of malaria treatment services: assessing inequities in consumers' perceptions and providers' behaviour in Nigeria. International Journal of Equity Health, 9, 22. https://doi.org/10.1186/1475-9276-9-22

Otubanjo, O. A., Mafe, M. A., Idowu, E. T. and Adeneye, A. K. (2000). Knowledge and perception of malaria in Lagos State, Nigeria. Nigerian Quarterly Journal of Hospital Medicine, 10(1), 73-77.

Oyibo, P. G. (2011). Out-of-pocket payment for health services: constraints and implications for government employees in Abakaliki, Ebonyi State, south east Nigeria. African Health Science, 11(3), 481-485.

Padonou, G. G., Gbenoudon, J. G., Osse, R., Salako, A., et al. (2018). Knowledge-attitudes-practices about malaria among communities in Southern Benin. International Journal of Public Health Science, 7(3), 186-193. https://doi.org/10.11591/ijphs.v7i3.14395

Rodriguez, A. D., Penilla, R. P., Henry-Rodriguez, M., Hemingway, J., Francisco, B. A. and Hernandez-Avilla, J. E. (2003). Knowledge and beliefs about malaria transmission and practices for vector control in Southern Mexico. Salud Publica de Mexico, 45, 110-116.

Rupashree, S., Jamila, M., Sanjay, S. and Ukatu, V. E. (2014). Knowledge, attitude and practices on malaria among the rural communities in Aliero, Northern Nigeria. Journal of Family Medicine and Primary Care, 3(1), 39-44. https://doi.org/10.4103/2249-4863.130271
Sabin, L. L., Rizal, A., Brooks, M. I., Singh, M. P., Tuchman, J. and Wylie, B. J. (2010). Attitudes knowledge, and practices regarding malaria prevention and treatment among pregnant women in Eastern, India. American Journal of Tropical Medicine and Hygiene, 82, 1010-1016. https://doi.org/10.4269/ajtmh.2010.09-0339

Saheed, O. U., Ipinmoye, T. O., Adu, A. S., Fadero, T., et al. (2015). Knowledge and practice of malaria prevention among nonmedical students of higher institutions in Ondo State, Nigeria. International Journal of Innovations in Medical Education and Research, 1, 1.

Salawu, A. T., Fawole, O. I. and Dairo, M. D. (2016). Patronage and cost of malaria treatment in private hospitals in Ibadan North LGA, South Western Nigeria. Annals of Ibadan Postgraduate Medicine, 2, 81-84.

Tarimo, D. S., Lwihula, G. K., Minjas, J. N. and Bygbjerg, I. C. (2000). Mothers' perceptions and knowledge on childhood malaria in the holendemic Kibaha district, Tanzania: implications for malaria control and the IMCI strategy. Tropical Medicine International Health, 5(3), 179-184. https://doi.org/10.1046/j.1365-3156.2000.00537.x

Tobgay, T. and Lhazeen, K. (2010). Malaria perceptions and practices in Bhutan. Southeast Asian Journal of Tropical Medicine and Public Health, 41(2), 274-279.

Uzochukwu, B. S. C., Ossai, E. N., Okeke, C. C., Ndu, A. C. and Onwujekwe, O. E. (2018). Malaria Knowledge and Treatment Practices in Enugu State, Nigeria: A Qualitative Study. International Journal on Health Policy and Management, 7(9), 859-886. https://doi.org/10.15171/ ijhpm.2018.41

Uzochukwu, B. S., Ughasoro, M. D., Etiaba, E., Okwuosa, C., Envuladu, E. and Onwujekwe, O. E. (2015). Health care financing in Nigeria: Implications for achieving universal health coverage. Niger Journal of Clinical Practice, 18(4), 437-444. https://doi.org/10.4103/1119-3077.154196

World Health Organization. (2015). Global Technical Strategy for Malaria. Available at: https://www.who.int/malaria/ areas/global_technical_strategy/en/ (Accessed: 30 October 2020).

World Health Organization. (2017). World Malaria Report, 2017. Available at: https:/www.who.int/malaria/ publications/world-malaria-report-2017/en/ (Accessed: 30 October 2020). 